CEREBRAL CIRCULATION IN THE NEONATE: ASSESSMENT USING TRANSCEPHALIC IMPEDANCE AND DOPPLER ULTRASOUND Colditz PB, Valimaki IAT, Murphy DF, Rolfe P, Wilkinson AR

Biomedical Engineering Centre and Department of Paediatrics. University of Oxford, John Radcliffe Hospital, Oxford OX3 90U, UK It has been suggested that fluctuations in arterial blood pressure and cerebral arterial flow velocity (CAFV) alter brain perfusion and lead to intraventricular haemorrhage (Perlman et al, New Eng J Med 309: 209, 1983). Although intermittent measurements of EAFV can be obtained by Doppler ultrasound, a major problem is the inability to monitor cerebral circulation continuously.

Experimental design: A microprocessor based technique of transcephalic electrical impedance $\left(\mathrm{dz}_{\mathrm{c}}\right)$ was used to monitor the cerebral circulation continuously (Murphy et al, in "Electronics in Medicine and 8iology", IERE, London 1986). Average $\mathrm{dZ}_{\mathrm{c}}$, arterial blood pressure and heart rate were continuously displayed and stored. Measurements of avg $\mathrm{dZ}_{\mathrm{c}}$ amplitude were compared with intermittent values of CAFV (Angioscan III) obtained from the anterior cerebral artery. Neonates with birth weight $<1500 \mathrm{~g}$ were studied for the first 48 hours. Those who received either indomethacin or aminophylline were studied before and for one hour after the dose.

Results and comments: In the 48-hour studies $(n=3)$ the $r$ values for the intraindividual correlation between avg $\mathrm{dz}_{\mathrm{c}}$ and mean CAFV were $0.40,0.70$ and 0.74 (all $p<0.05$ ). In the l-hour studies $(n=5)$ indomethacin caused a decrease of 25 $30 \%$ in both signals. CAFV is an estimate of blood flow in the anterior cerebral artery whereas $\mathrm{dz}$ reflects giobal changes in instantaneous intracerebral pulsatile blood volume. Our preliminary results suggest a relationship between these signals.

Financial support: The Medical Foundation - University of Sydney; the English Speaking Union and Nestle (PBC): The British Council, Turku University Foundation, and Academy of Finland (IATV).

\section{VISCOSITY REDUCTION OF RED BLOOD CELLS FROM PRETERM AND FULL-TERM NEONATES AND ADULTS IN NARROW TUBES Linderkamp 0, McKay CB}

(Dept. Pediatr., Univ. Heidelberg, FRG)

In blood vessels as well as in artificial tubes with diameters of less than $500-\mu \mathrm{m}$, the blood viscosity decreases with decreasing diameter (Fahraeus-Lindqvist effect). The present study was designed to measure viscosity of red blood cells (RBC) from ten preterm infants, ten term neonates and ten adults by means of a capillary viscometer. RBC were suspended in buffer solution at hematocrits of $0.20,0.40$ and $0.60 \mathrm{l} / 1$. Tubes with diameters of 50,100 and $500-\mu m$ were perfused with these suspensions. At a given hematocrit viscosity in the $500-\mu \mathrm{m}$ tubes was not significantiy different among the preterm infants, term neonates and adults. Viscosity decreased significantly, at each of the adjusted hematocrits, in the three groups when going from a $500-\mu \mathrm{m}$ tube to a 50- $\mu \mathrm{m}$ tube. The viscosity reductions increased with increasing hematocrit. At a hematocrit of $0.601 / 1$, the viscosity reduction averaged $48 \pm 7 \%$ in the preterm infants, $42 \pm 8 \%$ in the term neonates and $35 \pm 5 \%$ in the adults, whereas the viscosity reductions at a hematocrit of $0.20 \mathrm{l} / 1$ were only $32 \pm 6 \%, 27 \pm 4 \%$, and $24 \pm 6 \%$ respectively. For the combined data, there were significant linear relations of the viscosity reduction in 50- $\mu \mathrm{m}$ tubes at a hematocrit of $0.601 / 1$ to the MCV $(r=0.67)$, to the variation coefficient of MCV $(r=0.56)$ and to the hemogiob in $F(r=0.48)$. The enhanced viscosity reduction of neonatal RBC in narrow tubes may contribute to the low vascular resistance in neonates. Moreover, the present data suggest that a high hematocrit does not impede blood flow in neonates as much as in adults, unless the neonatal
$\mathrm{RBC}$ are exchanged for adult RBC.

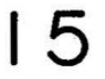

Calcium channel blockers in the prevention of perinatal ischemic brain damage.

H.C. LOU (John F. Kennedy Institute, Glostrup, Denmark) Ischemia plays a crucial role in the pathogenesis of perinatal brain damage; the sites of predilection are the watershed regions between different arterial supply systems, notably in periventricular leukomalacia. Cerebral blood flow (CBF) studies in the immediate postnatal period have shown a strong correlation between low neonata? CBF and subsequent neurologic and intel lectual development. Furthermore, ischemia seems to be the major determinant of subsequent periventricular hemorrhage which in turn may induce secondary regional perihemorrhagic ischemia.

Counteracting perinatal cerebral ischemia may, therefore, be a reasonable approach in the prevention of perinatal brain damage. In experiments with newborn sheep, it has been shown that administration of Nimodipine, a dihydropyridine channel blocker, increased CBF markedly in all brain regions in normo- and hypotension. We have found that calcium blockers, in particular Nimodipine, effectively blocks potassium induced vasoconstriction which presumably is of major importance in the development of perihemorrhagic ischemia. By decreesing calcium influx in neural cells calcium blockers may also limit hypoxic cell damage. We therefore suggest that controlled trials of Nimodipine on the effect of CBF and outcome should be carried out in carefuily selected patient groups.
16

Calcium and vascular smooth muscle contraction. G. PFITZER (Dept. Pediatrics, Div. Neonatology, Univ. of Heidelberg, Heidelberg, W-Germany)

Vascular smooth muscle contraction is triggered by a rise in the intracellular free $\mathrm{Ca}^{2+}$ concentration, the amplitude of the contractile activity being dependent on the magnitude of the calcium signal. The change in
the $\mathrm{Ca}^{2+}$ concentration can be due to an increased influx of $\mathrm{Ca}^{2}+$ from the extracellular space or to a release of $\mathrm{Ca}_{2}+$ from intracellular stores. The influx of $\mathrm{Ca}^{2+}$ occurs via two seperate pathways, i.e. through voltage dependent $\mathrm{Ca}^{2+}$ channels which are opened by depolarization of the cell membrane, and receptoroperated calcium channels which are opened by the interaction of agonists with their receptors. In contrast to striated muscles activation of smooth muscle involves the reversible phosphorylation of myosin by a specifickinase, the myosin light chain kinase which is activated by $\mathrm{Ca}^{2+}$ via the intracellular calcium receptor calmodulin. Although $\mathrm{Ca}^{2+}$ is the major determinant of the contractile activity, the response of the contractile apparatus to $\mathrm{Ca} 2+$ can be modulated over a wide range. Modulators are $\mathrm{H}^{+}$-ions and inorganic phosphate. wich may accumulate during hypoxia, and the cyclic nucleotide CAMP and CGMP which play an important role in vasodilation. The relation ship between $\mathrm{Ca}^{2+}$ and contraction may also be modulated by certain drugs (e.g. calcium antagonists).

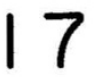

OXYGEN RADICALS STIMULATE PROSTAGLANDIN SYNTHESIS IN THE RAT SMALL INTESTINE

Poulsen,JP., BjфrO,K., Kreyberg, S., Saugstad,OD.

The National Hospital, oslo, Norway.

We studied the effects of oxygen radicals produced by Hypoxanthine (Hx) and xanthine oxidase (XO) on the rat small intestine to see whether this model could mimic the intestinal damage seen in infants with Necrotizing Enterocolitis(NEC). In anesthetised rats the ilium was divided with a silk suture preserving the blood supply into eight $5 \mathrm{~cm}$ long segments. Each loop was injected with $0,5 \mathrm{ml}$ of Ringer acetat or $\mathrm{Hx} 1 \mathrm{mM} / 1$ dissolved in Ringer plus $0,1,2$ or 5 units of xo. After 2 hours the animals were sacrificed, the loops of the intestine taken out, and the following parameters measured: Fluid volume(ml), electrocytes (mmol/1) and prostaglandins $(\mathrm{pg} / 0,1 \mathrm{ml})$ in the intestinal fluid. Results:

\begin{tabular}{lllllll} 
Xo & Volume & Na & $\mathrm{K}^{+}$ & $\mathrm{Cl}^{-}$ & PGF & 6 -keto PGF \\
\hline 1 & 0,28 & 205 & 13 & 22 & 358 & 110 \\
\hline 2 & 0,34 & 196 & 11 & 34 & 453 & 194 \\
\hline 5 & 0,92 & 162 & 11 & 58 & 818 & 568 \\
\hline $\mathrm{p} S$ & 0,001 & 0,05 & NS & 0,05 & 0,05 & NS \\
\hline
\end{tabular}

also studied by light microscopy: In rats given $5 u$ of $x o$ there was haemorrhage into mucosa and muscularis propria with necrosis of villi. Several of the rats showed pronounced oedema. These findings were considerably less marked with smaller concentrations of $x O(p \leqq 0,05)$. The present model demonstrates that the $\mathrm{Hx} / \mathrm{xO}$ system potently affects biochemical functions of the small intestine. With high concentrations of $x o$ the mucosa, the muscularis propria and the villi are damaged, and we speculate whether this might represent the pathogenesis of NEC. Further, these experiments suggest that oxygen radicals can stimulate prostaglandin synthesis in the small intestine.

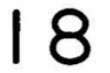

BLOOD VOLUME OF PRETERM NEONATES DURING FLUID RESTRICTION

Versmold H, Arleth S, Leifels-Fischer B, Linderkamp 0 . Div. Neonatology, Frouenklinik, Univ. of Munich, FRG

Fluid restriction in neonates reduces the incidence of patent ductus arteriosus and intracranial hemorrhage, enhances the elimination of excess lung water, but may cause hypovolemia with impaired renal and cerebral blood flow. We studied changes in blood volume (BV) during a loss of $10 \%$ of body weight in 10 AGA infants of $750-1500 \mathrm{~g}$ ofter birth, at the time of minimal weight $(3.2+1.3 d)$ and when birth weight was regained $(11+3 d)$. Plasma volume (PV) was measured by the Evans Blue dilution technique, BV and RBC mass were calculated from PV and venous HCT. Results (mean $\left.\pm \mathrm{SD}^{*}{ }^{*} p<0.05\right)$ are given in the table:

\begin{tabular}{|c|c|c|c|}
\hline & After birth & Min.Weight & Re Birth Weight \\
\hline Weight (g) & $1235 \pm 231$ & $* 1112 \pm 182$ & $1257 \pm 196$ \\
\hline Fluids ( $\mathrm{ml} / \mathrm{kg} . \mathrm{d})$ & $69.6 \pm 9.6$ & $* 117.6 \pm 21.6$ & $141.6 \pm 21.6$ \\
\hline BV $(\mathrm{ml} / \mathrm{kg})$ & $82.4 \pm 4.7$ & $76.3 \pm 5.3$ & $83.4 \pm 3.7$ \\
\hline$P V(\mathrm{ml} / \mathrm{kg})$ & $43.7 \pm 4.3$ & $45.4 \pm 4.3$ & $51.3 \pm 4.5$ \\
\hline RBC mass $(\mathrm{ml} / \mathrm{kg})$ & $38.7 \pm 5.7$ & $30.9 \pm 2.5$ & $32.1+4.0$ \\
\hline 02 capacity $(\mathrm{ml} / \mathrm{dl})$ & $23.1 \pm 2.3$ & $20.6 \pm 1.2$ & $19.0 \pm 2.3$ \\
\hline Systol. $B P(\mathrm{mmHg})$ & $49.4 \pm 4.6$ & $51.4 \pm 4.9$ & $50.4 \pm 5.0$ \\
\hline Urine $(\mathrm{ml} / \mathrm{kg}, \mathrm{h})$ & $1.5 \pm 0.9$ & $4.7 \pm 0.8$ & $4.0 \pm 1.0$ \\
\hline
\end{tabular}
When weight decreased by $10 \%$, BV decreased by $7.5 \%$. This reduction of BV was not associated with hypotension or oliguria. It may not increase the risk of hypoxic ischemic encephalopathy. Amarked fall in $R B C$ mass and 02 capacity, despite substitution of sampled ditional RBC transfusion appearse. To maintain RBC mass, ad- 